\title{
Dynamic Energy Modelling For Ship Life-Cycle Performance Assessment
}

\author{
Jakub Cichowicz ${ }^{1}$, Gerasimos Theotokatos ${ }^{2}$ and Dracos Vassalos ${ }^{2}$, \\ 1 Safety at Sea Brookes Bell, UK \\ 2 Department of Naval Architecture, Ocean \& Marine Engineering, University of Strathclyde, Glasgow, \\ Scotland, UK
}

\begin{abstract}
This paper summarises related work undertaken by the EC-funded Research Project TARGETS, which focuses on assessing energy efficiency by a direct approach. Energy flows onboard ships are considered in the time domain for complete ship energy systems simulation, allowing for interactions at system and component levels and accounting for different configurations, operating profiles, itineraries and environmental conditions. The approach and tools form the basis for life-cycle energy management considerations, addressing design, operation and retrofitting. To demonstrate the methodology leading to the evaluation of performance-based energy efficiency and its anticipated impact on ship design and operation, a case study for containership is carried out. Results are presented and discussed, demonstrating considerable advantage in adopting a more systematic and scientific approach to address Energy Efficiency of ships.
\end{abstract}




\section{Introduction}

The Marine Environment Protection Committee (MEPC) at its $58^{\text {th }}$ session made noteworthy progress in developing technical and operational measures to address GHG emissions. The outcome was the development of the Energy Efficiency Design Index (EEDI) for new ships as well as the Energy Efficiency Operational Indicator (EEOI) and the Efficiency Management Plan for all ships. These developments constitute a voluntary code on best practice in energy efficiency of ship operations. At its $59^{\text {th }}$ session MEPC disseminated interim guidelines on the method of calculation, and verification of EEDI for new ships, along with guidelines on the development of a Ship Energy Efficiency Management Plan (SEEMP) and for voluntary use of the EEOI for new and existing ships. Subsequent MEPC sessions adopted a number of amendments of the initially proposed indices, aiming to finalise the EEDI implementation methodology (IMO, 2011, 2012a, 2012b).

Although the establishment of EEDI is a straightforward and encouraging step towards the greening of ship operations, and it builds on a holistic approach as it addresses the issues from the design stage, it suffers from a series of deficiencies in its implementation:

- It represents the ship transportation $\mathrm{CO}_{2}$ efficiency at a single point during the life span of the ship.

- Larger cargo carrying capacity (payload) of the ship leads to improved EEDI since the capacity term is in the denominator. This renders larger ships more environmentally friendly than smaller ones.

- The ship electric power in the formulation depends on the installed main engine power. This can be misleading since the installed electric power capacity depends on the ship mission, various safety margins, classification rules, etc. As a result of this the less-comprehensive approach, undersized machinery may appear beneficial.

The intention in introducing EEDI was to stimulate innovation, technical development and operational improvement of all elements influencing the energy efficiency of a ship. This effort and development deserves and needs further support by the industry and academic community.

In this respect, following closely the recently trodden path of performance-based design and the use of firstprinciples tools to meet key objectives during the concept design stage, it is now time to tackle energy efficiency from a foundation of science and contemporary knowledge and technology. The development and use of EEDI, in its current formulation by IMO, has indeed played a catalytic role in motivating the maritime industry and 
creating a surge of activity with focus on energy and environmental performance of ships, in an unprecedented way. The instrument being used, however, has played and completed its role. Continuing to use EEDI in its current form and applying in ship design this ill-gotten constraint is likely to undo all the benefit harnessed to date. To safeguard against such developments, research effort has embraced once again first principles to pave a more rational way forward.

This paper introduces a methodology of assessing the dynamic energy performance of a ship at global level for any given period of time. For this purpose, all energy systems onboard are modelled and integrated into an overall energy model, which is subjected to a set of environmental conditions and operational requirements. In this manner, the energy flows onboard are presented as a function of time. The proposed methodology, using the term Dynamic Energy Modelling (DEM) has been adopted in the EC-funded project Targeted Advanced Research for Global Efficiency of Transportation Shipping (TARGETS, 2014), which was jointly funded by the $7^{\text {th }}$ Framework Programme and industry and was completed in March 2014. A brief description is provided in the following section.

DEM offers the much needed realistic simulation of ship energy systems over the ship life cycle which, when benchmarked against real-time measurements, can set a rational foundation for a performance-based assessment of ship energy efficiency and a comprehensive implementation process.

Making a measurable step in this direction and to demonstrate the methodology, key energy systems models of a containership are presented in this paper before addressing life-cycle energy considerations. Results are presented and discussed, demonstrating marked advantage in adopting a more systematic and scientific approach to address Energy Efficiency of ships.

\section{Dynamic Energy Modelling (DEM)}

The Dynamic Energy Modelling (DEM) concept that was developed in the TARGETS project (TARGETS, 2014) is a performance-based method, which captures holistically the transfer, conversion and storage of energy onboard a ship as a function of its operational profile and over long periods of time or during its commercial lifecycle. The foundation of DEM is comprised by the mature knowledge of (i) the hydrodynamic performance of ships, and (ii) the energy systems onboard a ship (internal combustion engines, auxiliaries, hydraulic and pneumatic networks, electrical networks, and HVAC systems). In this context, the main body of development is 
concerned with the compilation of energy modules pertaining to the performance of each system onboard, and their integration from local level to ship-level in order to create an overall ship energy system to be considered for implementation. This concept is schematically explained in Figure 1.

DEM is developed to be inherently modular, a fact justified by the need to assess alternative configurations of systems (especially during the design stage) and to identify the contribution of each system individually to the overall energy performance of the ship. The latter point is also linked to the optimisation (for a set of operational conditions) and energy management onboard, which are central to the energy performance of the ship. Moreover, the modularity of the methodology allows the integration and assessment of alternative sources of energy (solar, wind, fuel cells, etc.), which have recently started receiving attention in the maritime industry.

In the TARGETS project, a software tool has been developed which represents all relevant system components and their functional relationships. This has been implemented in a simulation environment (iSysE), which has been upgraded with a dedicated Graphical user interface to facilitate interaction. An example from iSysE environment is shown in Figure 2 and demonstrates the simulated ship power plant fuel oil consumption and power requirements of different components over a period of time with varying operational conditions such as speed variations, engine loadings and different conditions of auxiliary engines. The DEM approach has also been used in the REFRESH project (REFRESH, 2014), which is an another FP7 EC-funded project, focusing on optimising the energy efficiency of existing ships by retrofitting energy saving technologies as well as on the development of ship life-cycle energy management systems.

The DEM includes all relevant information on the dependencies of ship resistance and power requirements as functions of speed, trim and environmental conditions (random). Propeller performance data are included as well as the effects of increasing surface deterioration over time, which will affect ship resistance and thus power requirements. Thus, the DEM allows not only for simulating the behaviour of a given ship in an "as is" condition but also investigating the effects of different technical solutions aiming to improve energy efficiency, e.g. changing/polishing the ship propeller or retro-fitting energy saving devices as well as analysing the effects of different operational scenarios. 


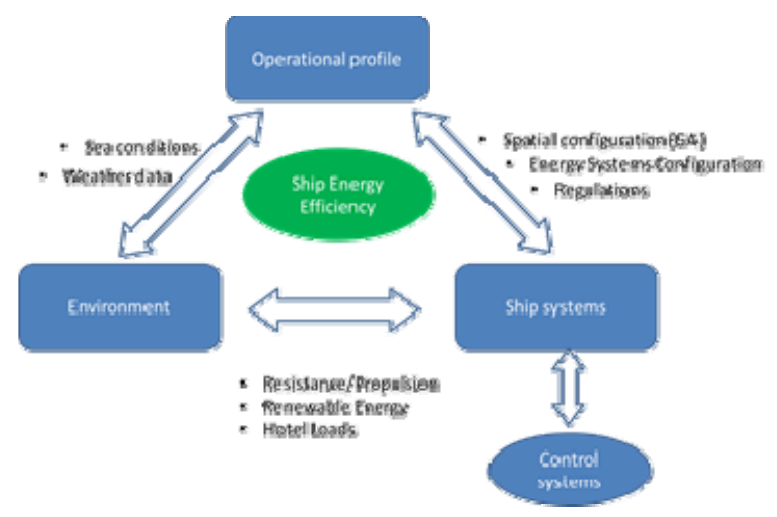

Figure 1 DEM Methodology Interactions.

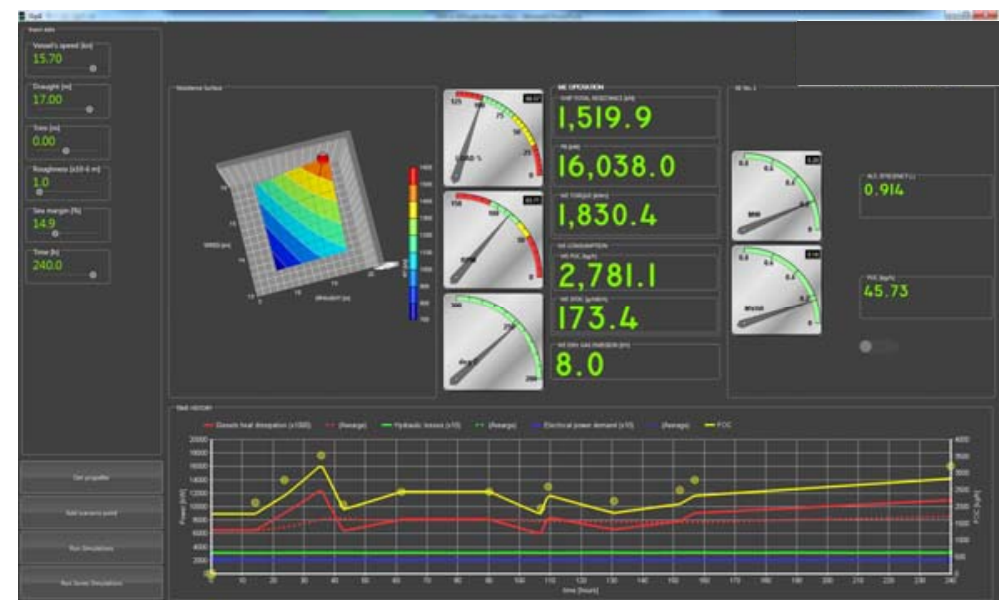

Figure 2 DEM Integration - sample results of simulations in the iSysE application.

\section{Modelling of Ship Systems}

\section{Propulsion system and diesel-generator sets}

The propulsion plant installation of a typical merchant vessel consists of the main engine, the shafting system and the propeller. Depending on the vessel type and size, the ship main engine can be two-stroke or four-stroke turbocharged marine Diesel engine. The shafting system comprises the connecting shafts and the bearings and additionally for the four-stroke type engines, a gear box installed between the engine crankshaft and the propeller shaft. The propeller is usually of fixed pitch type although, during recent years, designs with controllable pitch propellers have also been used. Two or more four-stroke auxiliary engines are installed to cover the required ship electric energy. A shaft generator is often installed in order to produce the required electric power during ship voyages, where the engine operates at relatively high load. 
One of the key requirements of the presented concept is the accurate modelling of the vessel main and auxiliary engines. In this respect, a modular mean value model, which was previously developed (Theotokatos, 2010) and extensively validated, is used. Each part of the engine is modelled using a separate block, which exchanges variables with the adjacent blocks of the model through the appropriate connections. Flow receiver elements (control volumes) are used for representing the engine receivers. These are interconnected with flow elements. Fixed fluid elements with constant pressure and temperature are used for modelling the engine boundaries. Shaft elements are used for representing the engine mechanical components. The engine governor element, which is used to adjust the engine fuel rack position, is of the proportional-integral type (PI) with the appropriate limiters. The propeller and ship elements are used for calculating the propeller and ship parameters, respectively. An electric generator block is used for calculating the electric generator torque.

\section{The model implementation in the MATLAB/Simulink environment for the case of the containership propulsion system is shown in}

Figure 3. The modelled engine elements form discrete subsystems, which exchange the required variables through appropriate connections. The flow elements use as input the pressure, temperature and the properties of the working medium (air or gas) contained in the adjacent elements (flow receiver(s) or fixed fluid), whereas their output includes the mass flow and energy rates entering and exiting the flow element as well as the absorbed (for the case of compressor) or produced torques. The former are provided as input in the adjacent flow receiver elements, whereas the latter is required as input in the shaft elements. The output of shaft elements, i.e. the engine crankshaft and turbocharger shaft rotational speeds, are supplied as input to the respective flow controller. The propeller element uses as input the propeller shaft speed (taken from the shafting system element) and ship speed (taken from the ship element, providing as output the propeller torque (to the shafting system) element and the propeller thrust (to the ship element). The detailed description of the used model can be found in Theotokatos (2010). A similar model was also used for simulating the ship diesel generator set by replacing the propeller/ship bocks with the electric generator block.

The flow receiver elements are modelled using the open thermodynamic system concept (Watson \& Janota, 1982). No heat transfer is taken into account for the scavenging air receiver, whereas the transferred heat from the gas contained in the exhaust gas receiver to the ambient is calculated using the exhaust gas receiver overall heat transfer coefficient and heat transfer area.

The engine cylinders bank is regarded as a flow element. For the two-stroke engines, the incoming air mass flow rate is calculated considering the equivalent of two consecutive orifices, each one representing the cylinders 
scavenging ports and exhaust valve, respectively (Meier, 1981). For the four-stroke engines, the pumping flow rate, which is a function of engine speed and volumetric efficiency, is additionally taken into consideration.

The mass flow rate of the exhaust gas, exiting the engine cylinders, is found by adding the mass flow rates of the air entering the engine cylinders and the injected fuel. The latter is calculated using the number of the engine cylinders, the engine rotational speed and the injected fuel mass per cylinder and per cycle. The injected fuel mass per cylinder and per cycle is regarded as function of engine fuel rack position. The energy flow rate exiting the engine cylinders element is calculated by taking into consideration energy conservation.

The indicated mean effective pressure is calculated using the rack position, the maximum indicated mean effective pressure of the engine and the combustion efficiency, which, in turn, is regarded as function of engine air to fuel ratio (Watson \& Janota, 1982). The friction mean effective pressure is considered as function of the indicated mean effective pressure and the engine crankshaft speed. The engine brake mean effective pressure is calculated by subtracting the friction mean effective pressure from the indicated mean effective pressure, whereas the engine torque is calculated using the brake mean effective pressure and engine cylinders displacement volume (Heywood, 1988).

The compressor is modelled using its steady state performance map, which is provided as input in a digitised form containing lines of the turbocharger speed, pressure ratio, corrected flow rate and efficiency. Given the turbocharger shaft speed and the compressor pressure ratio, the corrected flow rate and efficiency are calculated using interpolation. The turbine is modelled using its swallowing capacity and efficiency maps, which must be provided in digitised form. Given the turbine pressure ratio, the turbine mass flow rate and efficiency are calculated using interpolation. The temperature of the air exiting the air cooler is calculated based on the air cooler effectiveness definition equation (Watson \& Janota, 1982), using the air cooler effectiveness and the temperature of the cooling water entering the air cooler.

The engine crankshaft and turbocharger shaft rotational speed calculation is carried out in the shafting system and turbocharger shaft elements, respectively. The former uses the engine and propeller torques fed from the engine cylinders and propeller elements, respectively; the later uses the compressor and turbine torques supplied form the respective elements. The propeller torque is calculated by applying the propeller law equation passing through the engine maximum continuous rating (MCR) point. 
The engine crankshaft and turbocharger shaft rotational speeds are calculated by integrating the following equations, derived using the angular momentum conservation in the propulsion plant shafting system and the turbocharger shaft, respectively:

$$
\begin{gathered}
\frac{d N_{E}}{d t}=\frac{30\left(\eta_{S h} Q_{E}-Q_{P}\right)}{\pi\left(I_{E}+I_{S h}+I_{P}+I_{e w}\right)} \\
\frac{d N_{T C}}{d t}=\frac{30\left(Q_{T}-Q_{C}\right)}{\pi I_{T C}}
\end{gathered}
$$

\section{Exhaust Gas Emissions Calculation}

In order to calculate the engine carbon dioxide $\left(\mathrm{CO}_{2}\right)$ and sulphur dioxide $\left(\mathrm{SO}_{2}\right)$ gaseous emissions, the concept of perfect combustion in excess air is used (Heywood, 1988), which is justified by the fact that the substances produced by the chemical reactions other than the perfect fuel combustion e.g. carbon monoxide, unburnt hydrocarbons, nitrogen oxides, etc. form less than $0.5 \%$ of the exhaust gas volume (Henningsen, 1998). In addition, the nitrogen oxides (NOx) were estimated based on their expected concentration in the exhaust gas depending on the engine type and the used fuel (Scappin et al, 2012), (Henningsen, 1998). A detailed description of the exhaust emissions calculation procedure is given in Theotokatos \& Tzelepis (2013).

\section{Propeller Modelling}

The propeller element uses as input the propeller rotational speed and the ship speed, which are supplied from the engine shaft element and the ship element, respectively. Its output variables include the propeller torque and thrust; the former is forwarded in the engine shaft element, whereas the latter is provided in the ship element. The ship propeller torque and thrust are calculated by using the following equations based on the nondimensional coefficients of torque and thrust respectively, the sea water density the propeller rotational speed and the propeller diameter:

$$
Q_{P}=k_{Q} \rho_{s w} N_{P}^{2} D_{P}^{5}, \quad T_{P}=k_{T} \rho_{s w} N_{P}^{2} D_{P}^{4}
$$

The non-dimensional torque and thrust coefficients in open water conditions are calculated using the interpolation polynomials for Wageningen B-screw series, including Reynold's number corrections (Carlton, 2007) in the first quadrant. Appropriate correction factors are used for addressing other propeller types and propeller fouling. The propeller pitch to diameter ratio, expanded area ratio, number or blades and advance coefficient are required as input. 
The speed of advance is calculated using the ship linear velocity and the ship wake fraction coefficient; the latter can be estimated either from model tests or using semi-empirical formulae and is usually assumed as constant taking values in the region from 0.20 to 0.45 for ships with a single propeller operating in a wide range of ship speeds (Bertram, 2012). When a propeller is submerged in water and rotates as part of the vessel shafting system, the propeller polar moment of inertia is increased due to the water entrained by the propeller movement. There are several semi-empirical equations that estimate the entrained inertia (Korotkin, 2009).

\section{Ship Longitudinal Movement Modelling}

The ship longitudinal velocity is calculated by integrating the following equation, which is derived from ship motion dynamics:

$$
\left(m_{S}+m_{\text {hydro }}\right) \frac{d V_{S}}{d t}=T_{P}-F-R_{S}
$$

The ship resistance is evaluated as a function of ship shape, speed, hull roughness and environmental conditions. It was estimated at calm water conditions by using the Holtrop method (Holtrop \& Mennen, 1982). The increase of ship resistance depends on the hull fouling and in the encountered environmental conditions, including wind, wave and current. In very adverse weather conditions and especially in head seas and high sea states, the ship resistance can increase as much as $100 \%$ in comparison to the respective value at calm water conditions (MAN Diesel \& Turbo, 2012).

In addition to the ship mass, the ship surge-surge added mass is considered, calculated according to the semiempirical equation given in Oltmann (2003) as function of the ship displacement and block coefficient. The thrust deduction is calculated using the thrust deduction factor. The thrust deduction factor can be considered to have a constant value, typically in the region from 0.12 to 0.30 for ships with a single propeller or to be dependent on the ship speed.

\section{Typical results for the engine and the D-G sets of the investigated containership are presented in}

Figure 4. It is inferred that the model accuracy in both cases is quite sufficient for use in the DEM software. In addition, the engine degradation throughout the engine lifetime and its respective performance/emissions variation can be taken into account by calibrating the model based on ship operational data. 


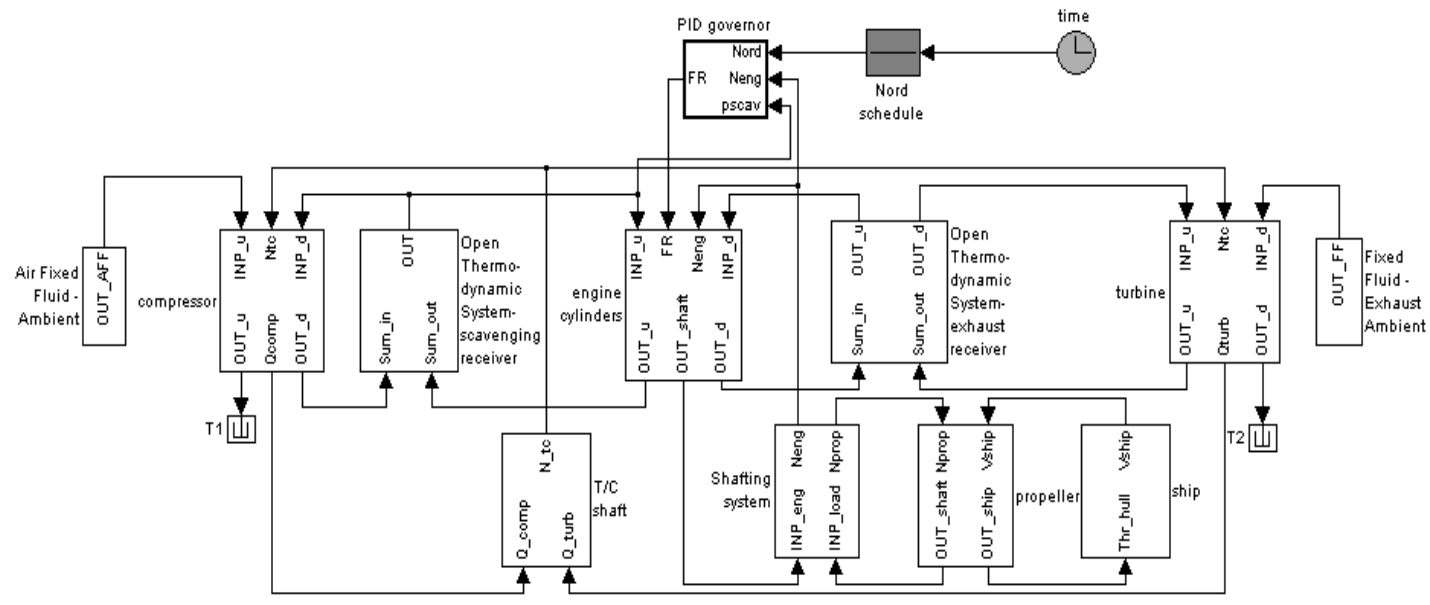

Figure 3 Ship propulsion plant model implementation in MATLAB/Simulink environment.
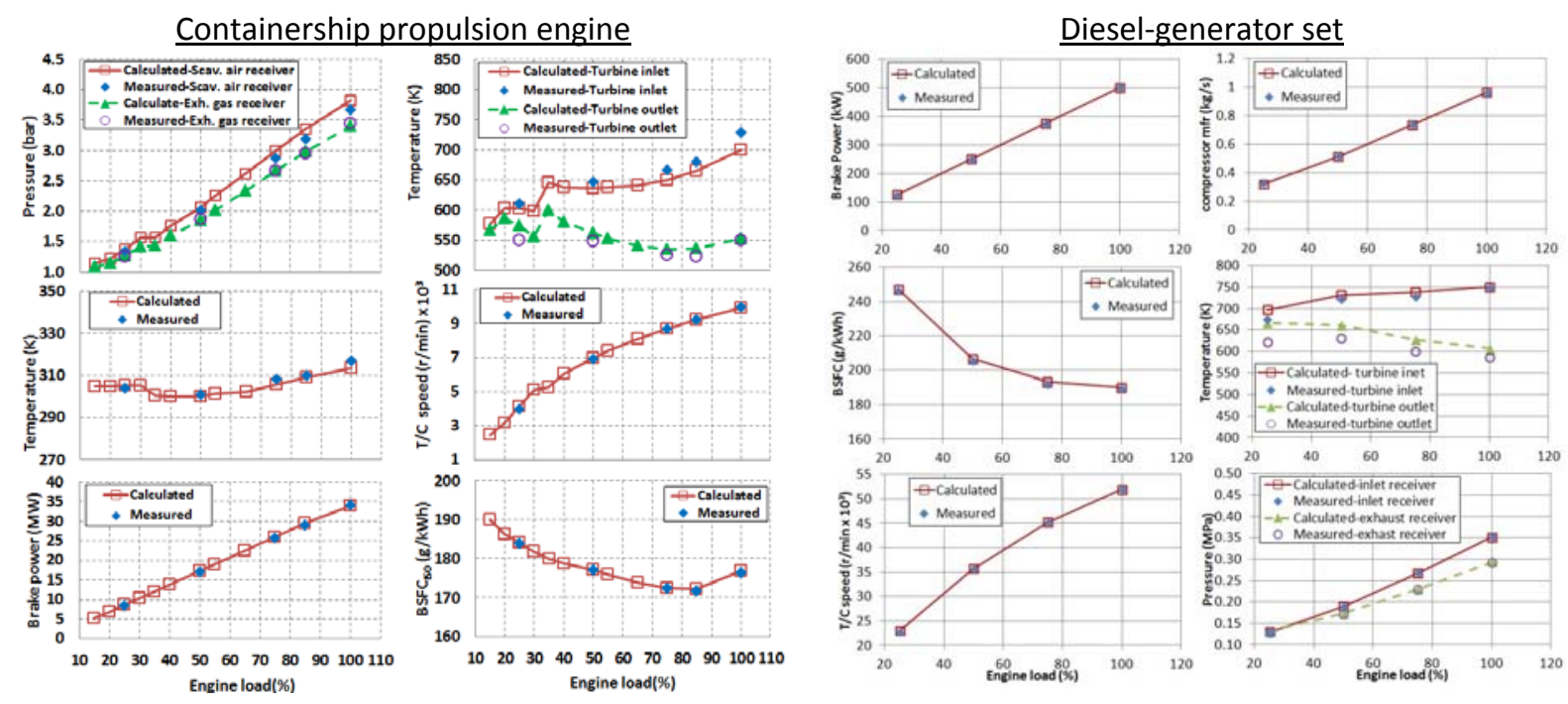

Figure 4 Simulation results for a container ship main engine (left) and Diesel-Generator set (right) and comparison with the respective shop tests data.

\section{Ship auxiliary systems}

Ship auxiliary systems for DEM are modelled by using the integrated system modeller (iSysE), an in-house software solution developed at Brookes Bell/Safety at Sea. The software contains a library of generic and customisable components such as diesel engines, electrical machines, pumps, valves, control systems etc. that can be used to set up the integrated ship auxiliary system models.

The auxiliary systems model comprises a series of interlinked graphs representing functionality and functional relations between individual systems, subsystems and components. In a general case the basic auxiliary model 
consists of two layers - the first represents the thermo-hydraulic network, whereas the second models the electric distribution grid along with the power managements system.

The operation of the integrated thermo-hydraulic system is modelled by using the governing equations derived by applying the mass conservation equations in the system nodes, the extended Bernoulli equation in the system branches and the energy conservation equation in the system heat exchangers (Janna, 1998).

The head loss in meters of the system branches is calculated by taking into account the friction loss and the fittings (valves, elbows, etc.) loss according to the following equation:

$$
\Delta h_{\text {loss }, i}=\left(f_{i} \frac{L_{i}}{D_{i}}+\Sigma K_{i}\right) \frac{Q_{i}{ }^{2}}{2 g A_{i}{ }^{2}}
$$

where $i$ denotes the $\mathrm{i}^{\text {th }}$ branch, $f$ is the friction factor, $L$ is the pipe length, $D$ is the pipe hydraulic diameter, $\Sigma K$ is the sum of loss coefficients of the fittings along the considered branch, $g$ is gravitational acceleration, $Q$ is the volumetric flow rate and $A$ is the pipe cross-section area.

The head increase of each pump is expressed in the form of the pump characteristic curves, in which the pump head is plotted against the volumetric flow rate. Quadratic polynomial equations are used for representing represent the pump characteristic curves. The electric power of each pump is calculated by using the following equation:

$$
P_{e l, i}=\rho g Q_{p, l} \Delta h_{p, l} / \eta_{i}
$$

where $i$ denotes the $\mathrm{i}^{\text {th }}$ pump, $\eta$ is the pump efficiency that includes the pump, the motor and the variable speed drive efficiencies. The motor and drive efficiencies can be estimated according to the data contained in (US DOE, 1991).

System components subjected to dynamic changes (such as fans, pumps or control valves) are modelled directly as objects within the networks whereas those subjected to static loads are accounted for as a baseline electrical load on dedicated switchboard models. The external loads are introduced to the system models through the main engine model (as described in the previous section) as well as through a set of boundary conditions. The system outputs include: the volumetric flow rate at each branch, the fluid temperature at each branch, the operating 
points (volumetric flow rate, head and efficiency) of each pump, the thermal capacity of the heat exchangers (heaters/coolers) and the electric power demand of each pump.

The iSysE models for the heavy fuel oil (HFO) feed system and the electric power distribution grid (including power management) of the investigated containership are presented in Figure 5 and

Figure 6, respectively.

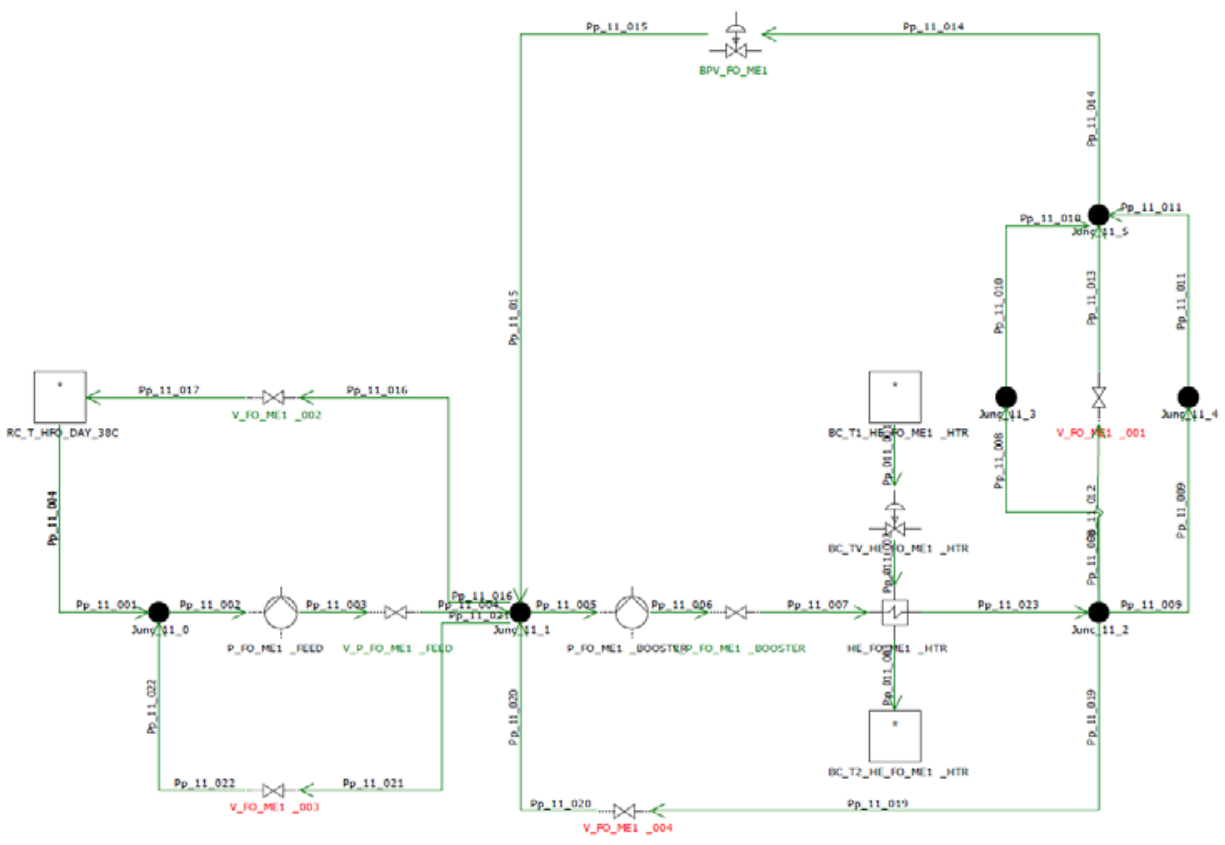

Figure 5 iSysE model of the investigated containership HFO feed system

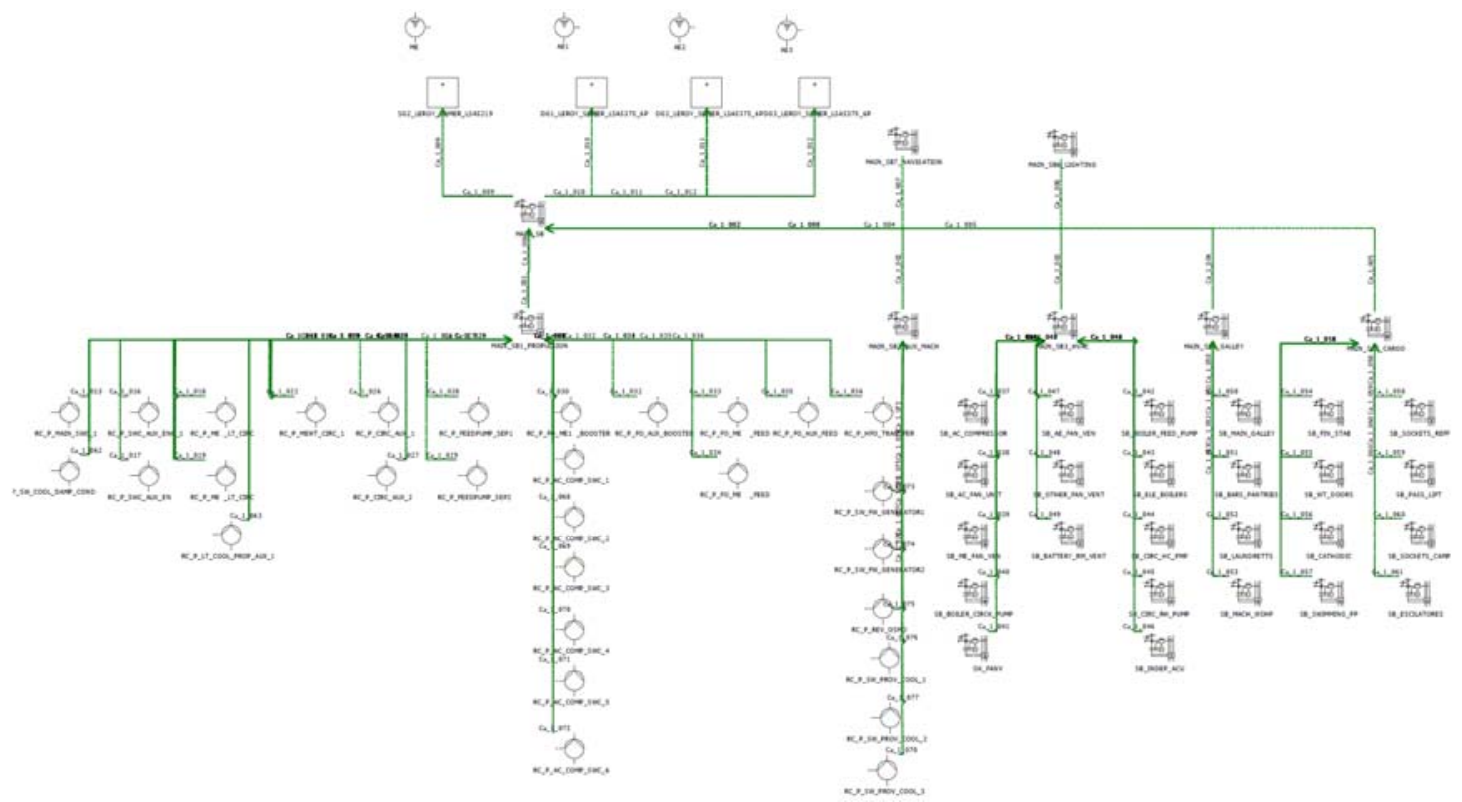

Figure 6 iSysE model of the investigated containership electric power distribution system 
The module of iSysE serving the purpose of time domain energy flow calculations (shown in Figure 2) has been designed in order to allow for adapting resolution of the models to the availability of data and the nature of the problem at hand. In applications that do not require monitoring of the state variables (e.g. plants without waste heat recovery system) or do not involve complex control the models effectively reduce to propulsion train and very basic model of power grid. The more complex plants, with diversified power sources governed by distributed control layers require more detailed, higher resolution models in order to reproduce behaviour of the interacting systems and components.

Irrespective of complexity of the models, integration of component-based models is formalised with use of matrix notation in which physical matter is discretised into material nodes connected through abstract links (i.e. entities largely based on pipes maintaining flow information and incorporating changes of energy and momentum. The node-link formalism has the following particularly important advantages. Firstly, it provides a simple and consistent way of modelling in which the entire topology of the system is prescribed by a single incidence (i.e. describing relationship between links and nodes) matrix. Secondly, the clear cut between nodes (the matter) and links (the interactions) allows for, at least, partial separation of substance and component models and this can be used for largely independent development of the framework. That allows for the module customisation, tailored or expanded (e.g. introducing new substances or components) without a need for any modification to the framework. Furthermore, the matrix "core" of the module allows for use of advanced mathematical tools of the matrix calculus and algebra for computational efficiency (e.g. convergence, sparsity) and for in-depth studies of the energy models. An example of the latter is use of the matrix formalism is the development of the in-built sensitivity and uncertainty toolbox, allowing for rapid assessment of local vulnerabilities of the complex systems (usually represented as cyclic graphs, i.e. with many components demonstrating self-dependency).

Specifically, the toolbox developed for iSysE allows for quantifying impact of physical dimensions (e.g. characteristics of a pump, a heat exchanger or an electric motor) of the system components on state variables. Thus, the toolbox allows identifying dominant parameters corresponding to state variables describing behaviour of the system. The results derived from the parameters sensitivity analysis to the fuel oil consumption (FOC) of one auxiliary engine (AE) of the investigated containership area presented in Figure 7. 
The results of sensitivity assessment are used as input for implementing the design of experiments (DoE) methodology to perform systematic numerical studies of the plants model. The output from the DoE is, in turn, used for designing response surfaces allowing for replacing the numerical models (requiring time domain evaluations) with multivariate regression models. The regression models offer satisfactory fits and can be successfully employed for rapid calculations without compromising accuracy of the prediction (i.e. for as long as the inputs are within ranges used to design the response surfaces). A sample response surface model for total fuel consumption (FC) is shown in Figure 8.

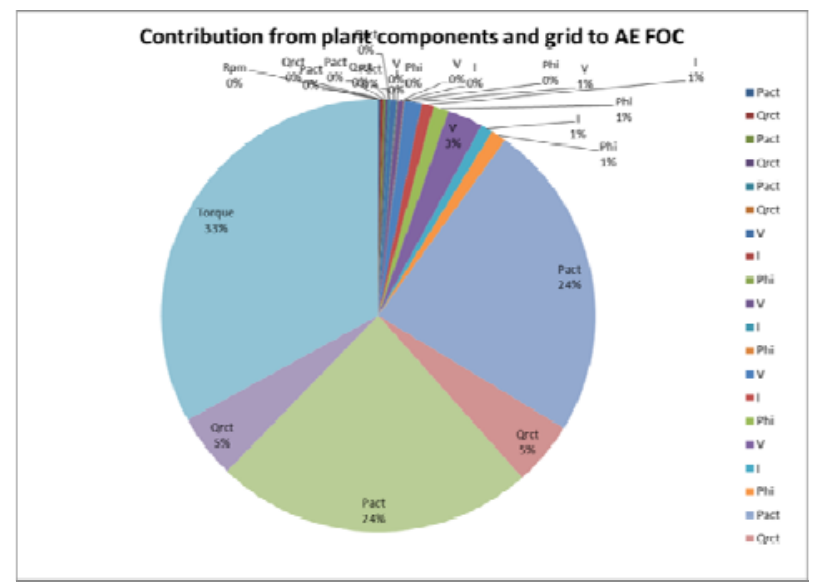

Figure 7 Results of parameter sensitivity derived for fuel consumption of an auxiliary engine

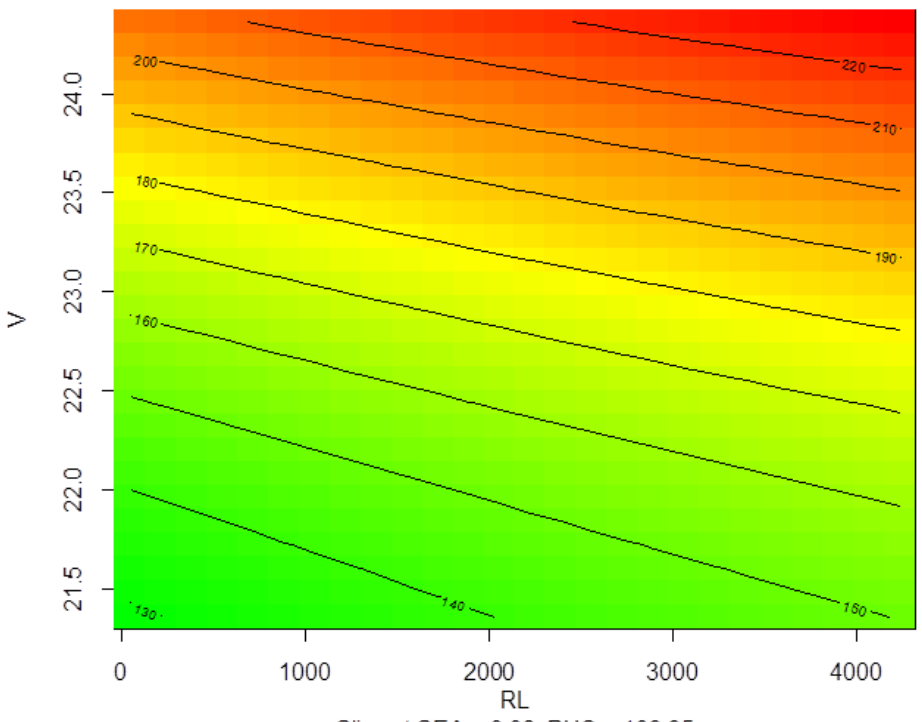

Figure 8 Total fuel consumptions $(F C)$ in $t$ /day (propulsion and auxiliaries) as a function of ship speed ( $V$ in knots) and electric reefer electric load ( $R F$ in $\mathrm{kW}$ ). 


\section{A strategy for life-cycle-performance-based energy efficiency assessment}

\section{The Concept}

The EEDI is a design index intended to benchmark energy efficiency of a new-built ship against the reference value, which in turn is derived from some statistical sample. The index is evaluated at some reference conditions with specific main engines (ME) break power, auxiliary electric load, deadweight and a ship speed that matches all these parameters. The way these reference parameters are chosen will vary with ship type and operational scenario but the philosophy remains unaltered.

Even in the presence of shaft generators, the calculations are straightforward and do not require the use of any complex tool. Furthermore, the resultant metric, i.e. amount of $\mathrm{CO}_{2}$ released per sailed nautical mile and tonne of transported cargo $\left(\mathrm{g} \mathrm{CO}_{2} / \mathrm{nm} / \mathrm{t}\right)$ is also a quite intuitive and convenient measure of carbon dioxide emissions. Unfortunately, whilst the main characteristics of the index, namely ease of calculations and robustness, offer a key advantage, the basic concept is rather unfounded as described in the foregoing and discussed extensively at IMO and in open literature.

The conceptual problem with EEDI originates from the notion "design index". The notion does not refer to a measure of energy efficiency of the design at some representative conditions. Instead, it refers to energy efficiency at the design or reference condition. At a glance the difference in notions seem vague, and in fact when the reference (design) conditions match well the ship's operational conditions over her lifecycle, the EEDI will be the representative measure. Should, however, the hypothetical and actual operational conditions differ significantly the index will become a notional instrument of no practical use. This is addressed in more detail in the following sections.

\section{Case study}

The case study presented in this section aims at investigating how the variations in key operational parameters such us ship speed, draught or hull roughness may influence the ship energy efficiency and subsequent $\mathrm{CO}_{2}$ emissions from propulsion and auxiliary plants of a merchant vessel.

\section{The ship}

The investigated vessel is a 3700 TEU containership of panama size having an overall length of $250 \mathrm{~m}$. 


\section{The Ship Energy Model}

The following ship energy systems are considered in this DEM case study:

- Propulsion system (incorporating calm water resistance, hull-propeller interaction, hull surface roughness and sea state corrections)

- Ship auxiliary engines, power distribution grid and power management system

- Sea water (SW) cooling system

- Fresh water (FW) cooling (high and low temperature loops) for main and auxiliary engines

- HFO transfer, purification and feed systems

- Lubricating oil (LO) service system

\section{Operational envelope}

In order to investigate various scenarios, it is assumed that all major operational parameters can be subjected to systematic variations. These include

- $\quad$ Speed (V)

- $\quad$ Draught (T)

- Auxiliary electrical load (RL)

In addition, the simulations accounted for the stochastic nature of sea states (drawn from uniform distribution). The sea state was incorporated into the results as an additional ME load $\left(\Delta P_{B}\right)$ varying from $0-15 \%$ of the ME service continuous rating $(\mathrm{SCR})$ point power.

Hull fouling, dry-docking and hull maintenance

The hull fouling was accounted for by a simple periodic model with linear deterioration of the clean hull smoothness, as presented in Figure 9.

The surface roughness increase was incorporated in the simulations as a total resistance correction $\left(\Delta R_{T}\right)$. 
Deterioration of diesel engines performance

Deterioration of main and auxiliary engines performance manifests itself as an increase in brake specific fuel consumption $(\triangle \mathrm{BSFC})$ due to wear and fouling of the engine components. Changing of engine ambient temperature can additionally be taken into account. An example of the BSFC percentage increase (compared to the sea trials BSFC values) throughout the engine lifetime is shown in Figure 10.

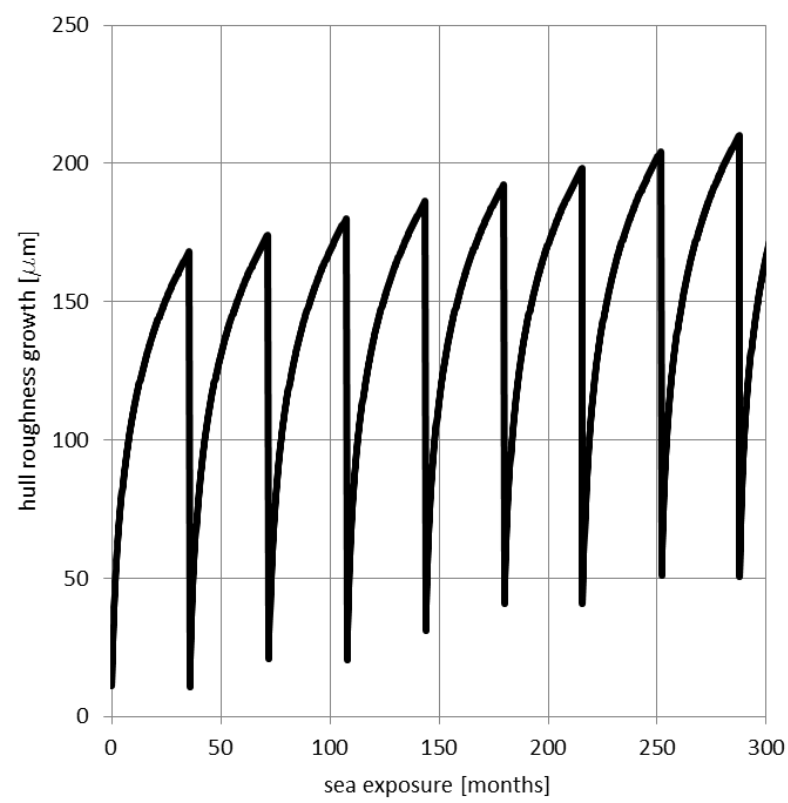

Figure 9 Model of hull surface roughness growth due to exposure to seawater. Assumed drydocking and hull cleaning every 36 months

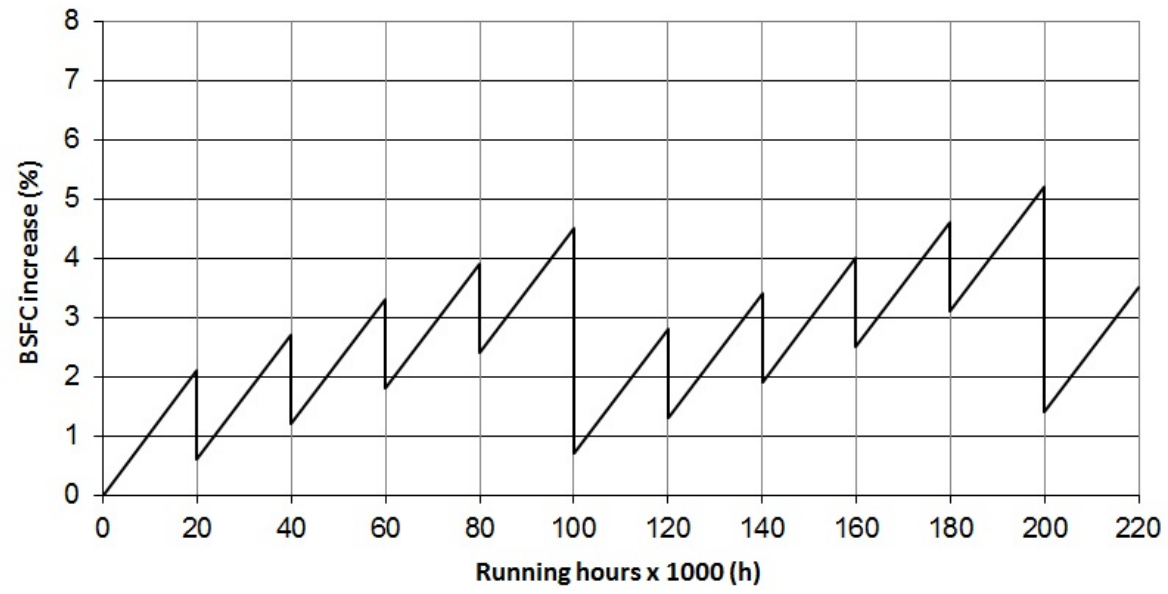

Figure 10 Deterioration of an engine performance due to wear and fouling of engine components 


\section{$\underline{\text { Results }}$}

The simulation results are presented for four hypothetical scenarios. In the first scenario, the investigated ship is subjected to random variations in all major operational parameters (speed $\mathrm{V}$, draught $\mathrm{T}$, hull roughness, RHO, varied based on sea exposed time and baseline electric load for reefer containers, RL). The results obtained are presented in Figure 11 and Figure 12. As shown in Figure 11, both the emissions calculated at the reference condition (denoted as Base) are very similar to IMO attained EEDI. The small difference is caused by the fact that EEDI links auxiliary engines FC to ME MCR power, whereas the load and BSFC for D-G sets are taken into account to calculate FC in the performed simulation runs.

As anticipated, the operational $\mathrm{CO}_{2}$ emissions deviate significantly from the IMO respective value. Specifically, hull roughness growth, reefer load and sea state have the strongest impact on the lifecycle-averaged emissions.

The second investigated scenario involved randomisation of the operational speed around a mean speed required to maintain the average (lifecycle) ME loads in calm water that match $75 \%$ of the engine MCR power. The obtained results are presented in Figure 13 and Figure 14. It can be readily seen from these figures that the impact of operational parameters on the lifecycle-averaged $\mathrm{CO}_{2}$ emissions is much weaker than that of the previous case. With the ship operated at a lower speed profile, the emission margin becomes negative (indicating specific $\mathrm{CO}_{2}$ emissions higher than the attained EEDI) only when the sea-state is accounted for.

The results obtained in this case also demonstrate much greater influence of draught, which was insignificant in the previous case. It is noteworthy that the influence of the sea state could to some extent be controlled, unlike the other parameters considered, for example through "weather routing". The third investigated case is another variation on the baseline profile, in which the average lifecycle speed matches the design speed but the ship operates at larger draughts (payloads).

The results are presented in Figure 15 and Figure 16. Similar trends to those of Case 2 were obtained; only the variation of sea state could specific $\mathrm{CO}_{2}$ emissions values greater than the attained EEDI value. The contour maps shown in Figure 16 indicate also reduced sensitivity of the $\mathrm{CO}_{2}$ emissions to variations of the sea state, reefer electrical loads and hull roughness.

The last examined case is yet another "corner" point in this hypothetical operational space, where the ship is assumed to operate within a lower speed envelope (as in Case 2) and at larger draughts (exceeding $70 \%$ of the 
ship's deadweight at the maximum draught, as in Case 3). The simulation results are presented in Figure 17 and Figure 18. In this case, the results indicate that even operation in waves would not cause the ship average $\mathrm{CO}_{2}$ emissions to exceed the IMO limits for (Phase I) EEDI.

The operational surface maps indicate much stronger nonlinearities in the emission profile than in the previous case. In this respect, these results are quite similar to those of Case 2.

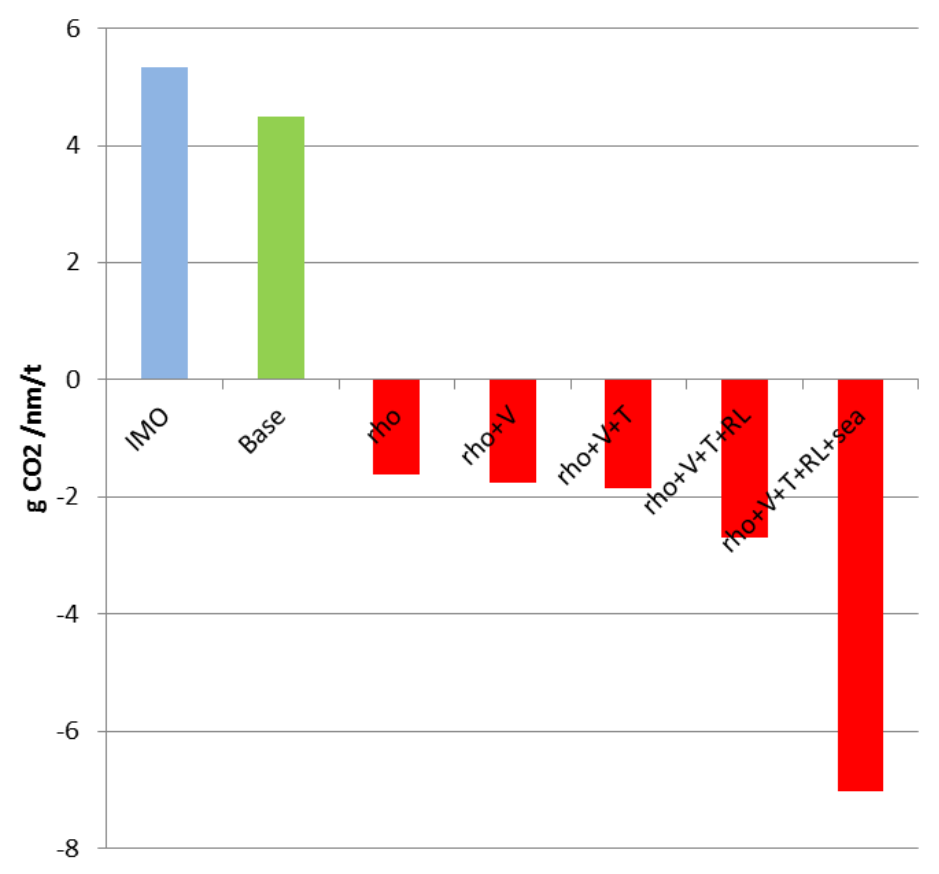

Figure 11 Impact of operational and environmental conditions on average (over lifetime) $\mathrm{CO}_{2}$ emissions in $\mathrm{g} / \mathrm{hm} / \mathrm{t}$ for Case 1. The results are presented as a difference between required (IMO baseline EEDI) and attained or calculated $\mathrm{g} C \mathrm{CO} / \mathrm{nm} / \mathrm{t}$. 


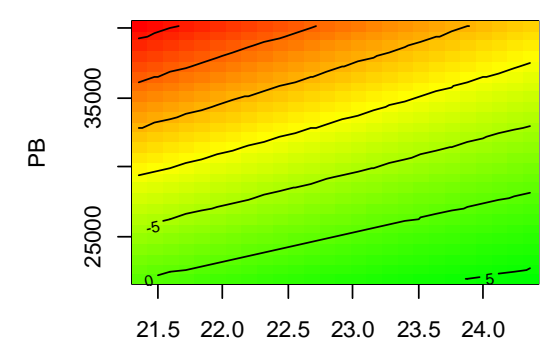

$\begin{array}{llllll}21.5 & 22.0 & 22.5 & 23.0 & 23.5 & 24.0\end{array}$

Slice at $\mathrm{SEA}=0.08, \mathrm{RL}=2103.94, \mathrm{RHO}=109.95$

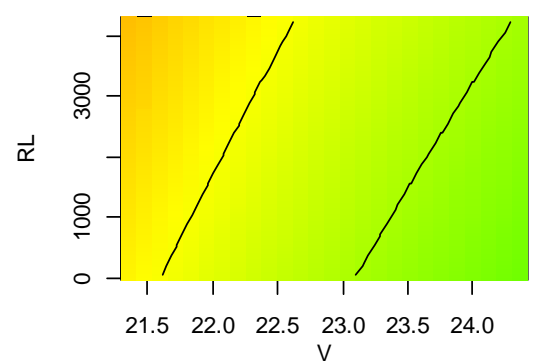

Slice at SEA $=0.08, \mathrm{RHO}=109.95, \mathrm{~PB}=31243.86$

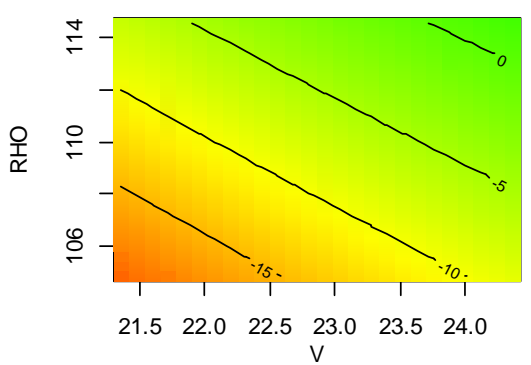

Slice at SEA $=0.08, \mathrm{RL}=2103.94, \mathrm{~PB}=31243.86$

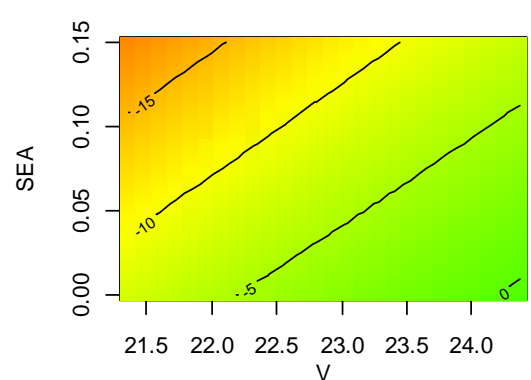

Slice at $\mathrm{RL}=2103.94, \mathrm{RHO}=109.95, \mathrm{~PB}=31243.81$

Figure 12 Contour plot slices at mean parameter values (e.g. top-right graph show contour map of $\mathrm{CO}_{2}$ emissions $\left(\mathrm{g} \mathrm{CO}_{2} / \mathrm{nm} / \mathrm{t}\right)$ as a function of speed and ME load at sample-averaged speed, roughness and sea-state correction). Should the vessel were operated within green ranges her $\mathrm{CO}_{2}$ footprint would always fall under the EEDI (Phase I) limit. PB: Brake power in $\mathrm{kW}$; RL: Reefer electric power in $\mathrm{kW}$; RHO: hull roughness in $\mu \mathrm{m}$; SEA: increase of power due to sea state (-).

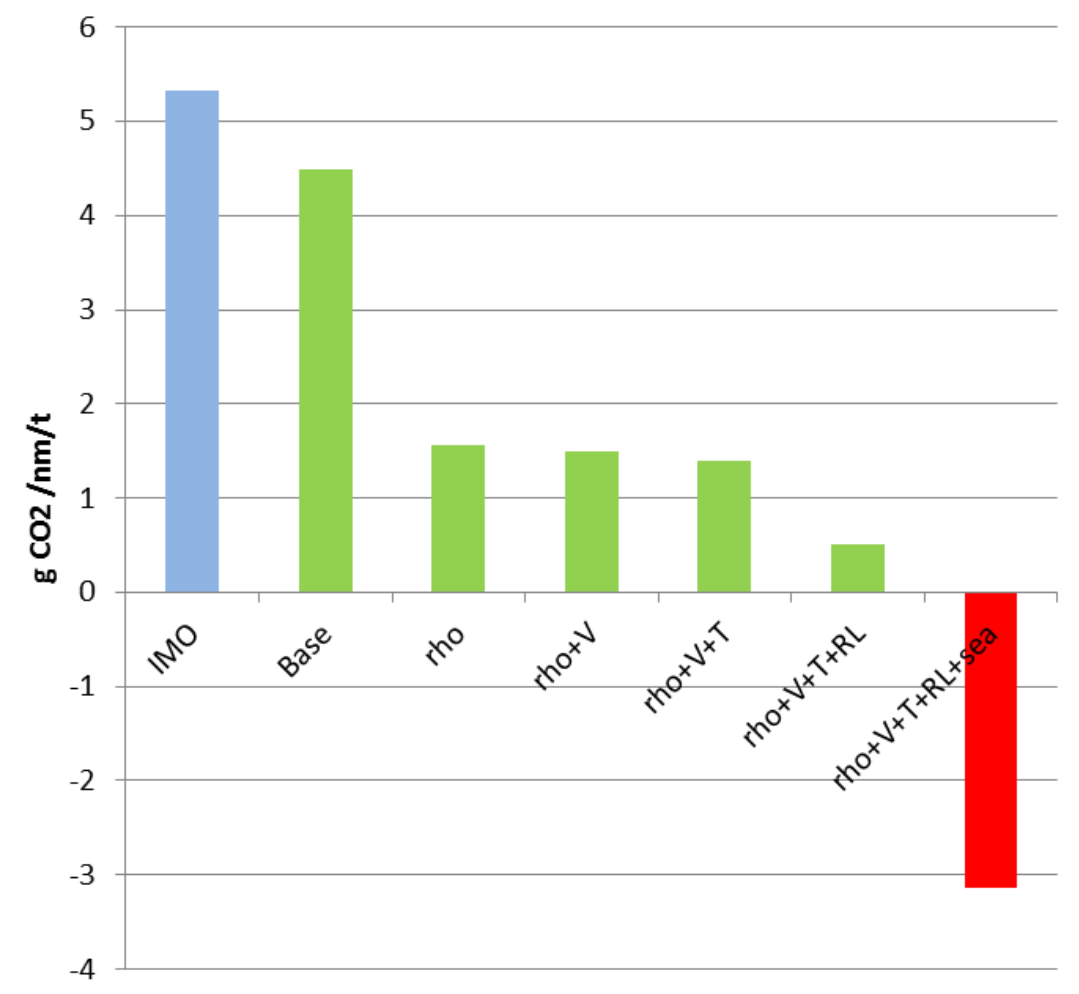

Figure 13 Difference from baseline EEDI in $\mathrm{g} \mathrm{CO} / \mathrm{nm} / \mathrm{t}$ calculated for Case 2. 


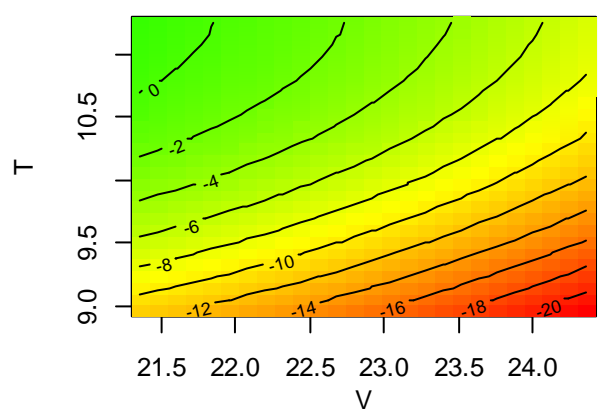

Slice at $\mathrm{SEA}=0.08, \mathrm{RL}=2103.94, \mathrm{RHO}=146.97$

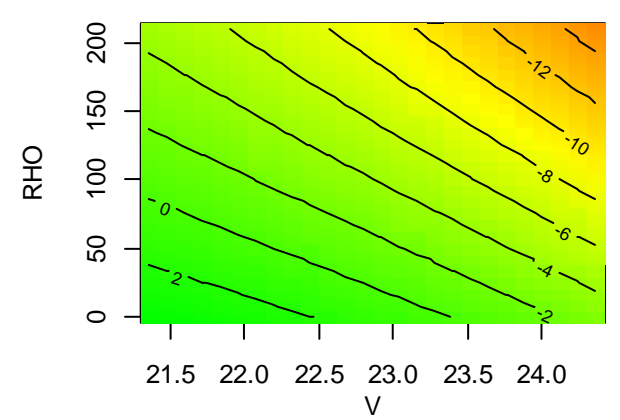

Slice at $\mathrm{SEA}=0.08, \mathrm{RL}=2103.94, \mathrm{~T}=10.11$

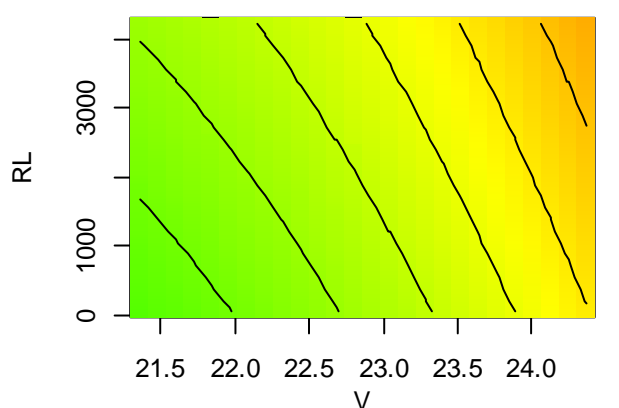

Slice at SEA $=0.08, \mathrm{RHO}=146.97, \mathrm{~T}=10.11$

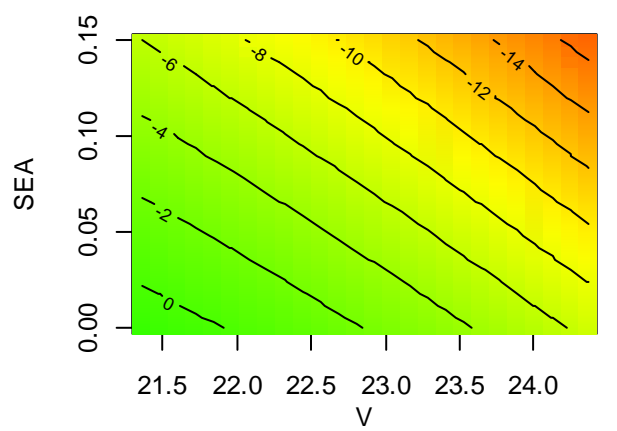

Slice at $\mathrm{RL}=2103.94, \mathrm{RHO}=146.97, \mathrm{~T}=10.11$

Figure 14 Variation of $\mathrm{g} \mathrm{CO} \mathrm{CO}_{2} / \mathrm{nm} / \mathrm{t}$ difference from baseline EEDI for Case 2; T: draught (m); V: ship speed (knots); RL: Reefer electric power in $\mathrm{kW}$; RHO: hull roughness in $\mu \mathrm{m}$; SEA: increase of power due to sea state (-).

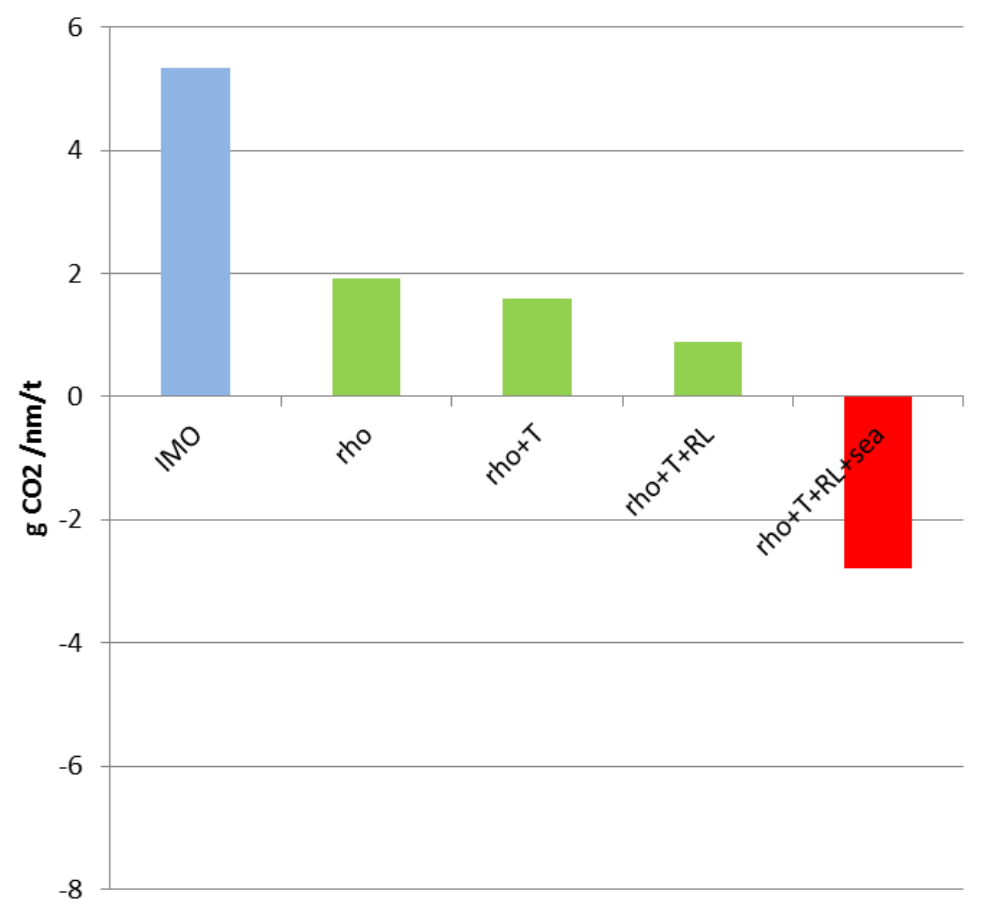

Figure 15 Difference from baseline EEDI in $\mathrm{g} \mathrm{CO} / \mathrm{nm} / \mathrm{t}$ calculated for Case 3. 


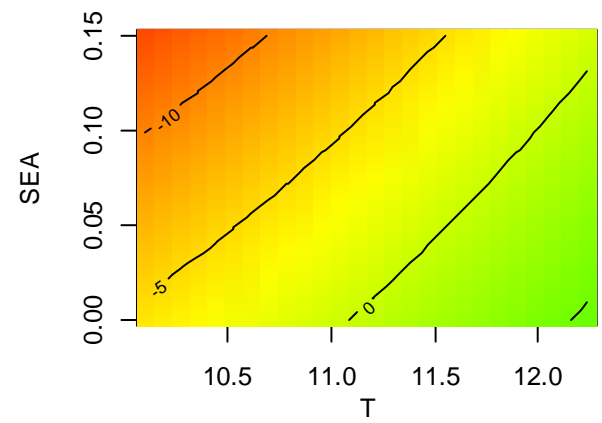

Slice at $\mathrm{RL}=2103.94, \mathrm{RHO}=146.97, \mathrm{~PB}=32134.0$

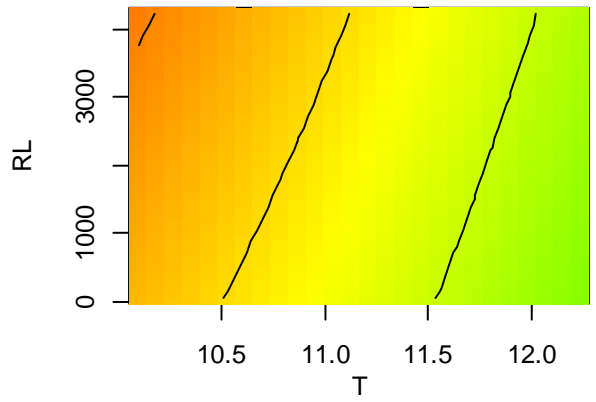

Slice at $\mathrm{SEA}=0.08, \mathrm{RHO}=146.97, \mathrm{~PB}=32134.04$

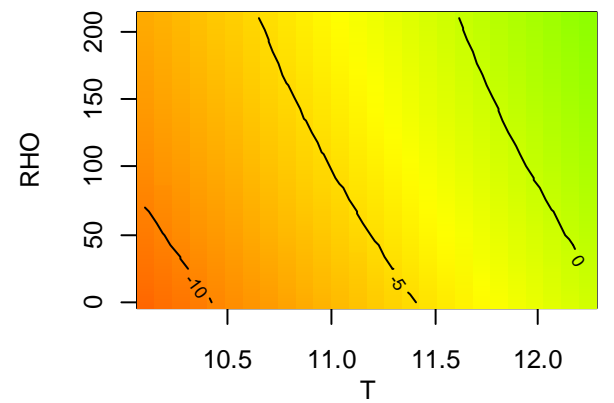

Slice at $\mathrm{SEA}=0.08, \mathrm{RL}=2103.94, \mathrm{~PB}=32134.04$

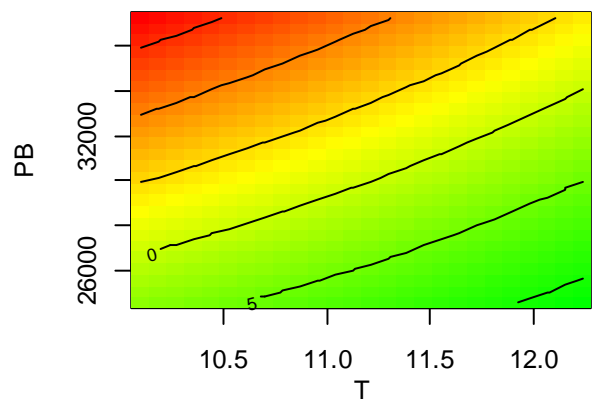

Slice at SEA $=0.08, \mathrm{RL}=2103.94, \mathrm{RHO}=146.97$

Figure 16 Variation of $\mathrm{g} \mathrm{CO}_{2} / \mathrm{nm} / \mathrm{t}$ difference from baseline EEDI for Case 3; T: draught (m); V: ship speed (knots); RL: Reefer electric power in $\mathrm{kW}$; RHO: hull roughness in $\mu \mathrm{m}$; SEA: increase of power due to sea state (-).

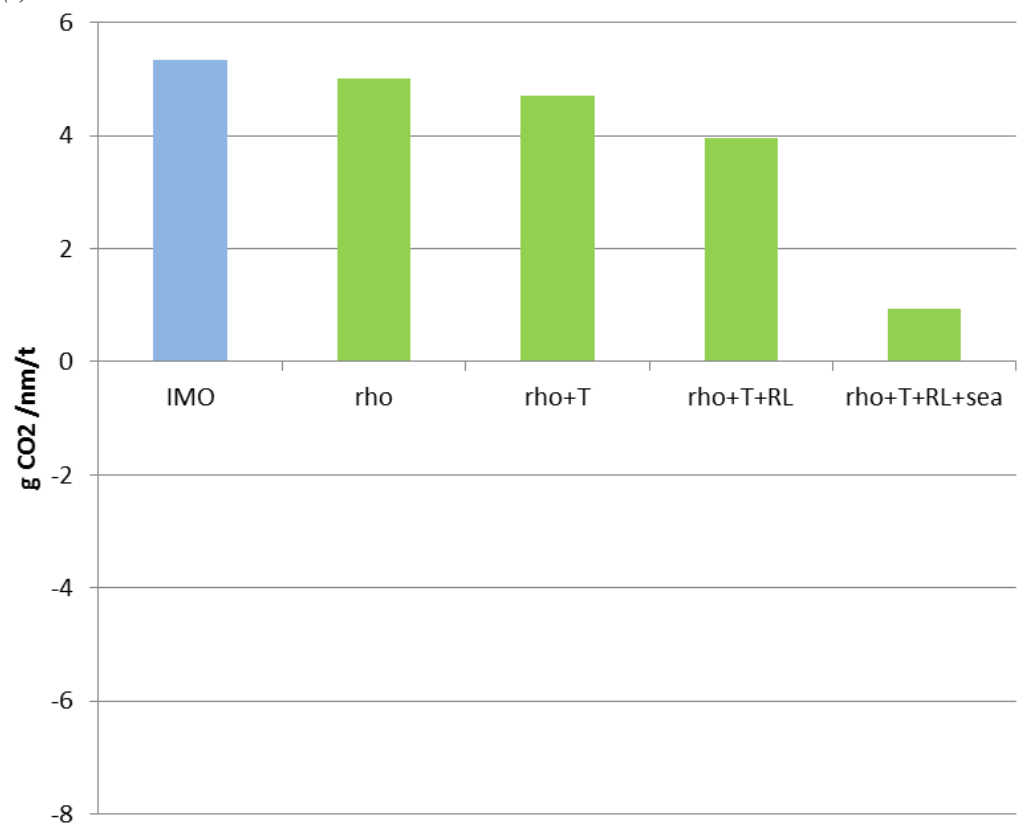

Figure 17 Difference from baseline EEDI in $\mathrm{g} \mathrm{CO} / \mathrm{nm} / \mathrm{t}$ for Case 4. 


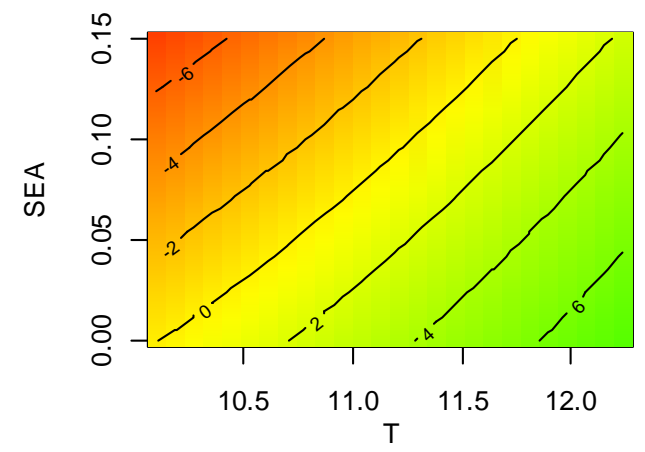

Slice at $\mathrm{RL}=2103.94, \mathrm{RHO}=146.97, \mathrm{~PB}=24843.1$ :

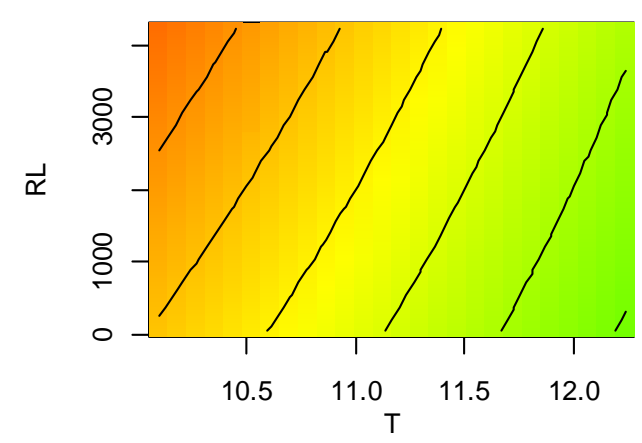

Slice at $\mathrm{SEA}=0.08, \mathrm{RHO}=146.97, \mathrm{~PB}=24843.12$
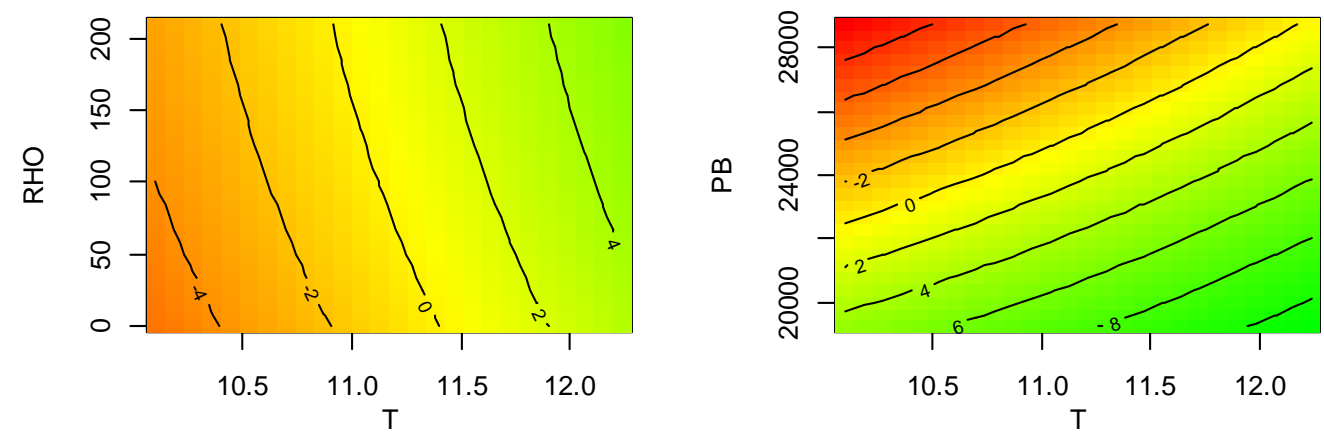

Slice at $\mathrm{SEA}=0.08, \mathrm{RL}=2103.94, \mathrm{~PB}=24843.12 \quad$ Slice at $\mathrm{SEA}=0.08, \mathrm{RL}=2103.94, \mathrm{RHO}=146.97$

Figure 18 Variation of $\mathrm{g} \mathrm{CO} / \mathrm{nm} / \mathrm{t}$ difference from baseline EEDI for Case 4; T: draught (m); V: ship speed (knots); RL: Reefer electric power in $\mathrm{kW}$; RHO: hull roughness in $\mu \mathrm{m}$; SEA: increase of power due to sea state (-). 


\section{Concluding Remarks}

The results presented in the previous section illustrate clearly is the influence of the operational profile on the $\mathrm{CO}_{2}$ footprint of a ship. Undoubtedly, one can argue that the results are somewhat "academic" and, as such unrepresentative of real scenarios. One can question further, if it is appropriate to make comparisons using operational emission measures (similar to the voluntary instrument introduced by IMO - the Energy Efficiency Operational Indicator - EEOI). Indeed both questions are valid, justified and in place. However, it was not the intention to discuss performance in "real" operation. Instead, the scenarios were designed to introduce boundaries in some feasible operational space. The "real" operation will take place somewhere within the limits set by all four cases. Hence, the intention is to generalise, not to analyse specific cases.

The second question is more important and the answer to it is NO. There is no point in comparing the operational efficiency indicator (as simulated) to the EEDI as the former is a measure of average efficiency of the design over its lifetime whereas the latter refers to a very specific point in the configuration space. However, even though such comparison is unjustified it is not because the operational indicator is an incomplete measure. The comparison is inappropriate because it is the EEDI that is incomplete and flawed. It is incomplete because it does not account for the entire life of a vessel; and it is flawed because it does not promote "green" operation. It does not account for hull and machinery maintenance; it does not account for heat recovery; it does not account for speed/routing/loading optimisation.

As a matter of fact the EEDI works well only while comparing ships not in operation. In all other cases the EEDI is bound to fail. It fails because it is sensitive but completely blind to variations in operational profiles and practices. This can be readily seen from the surface plots which even for cases 2, 3 and 4 show large areas where combinations of operational parameters lead to excessive $\mathrm{CO}_{2}$ emissions. On the other hand, even for Case 1 there are large areas on the surface plots where the emissions would convincingly meet the EDDI's targets. Yet, the EEDI does not capture this. In fact, in order to forge the EEDI into a robust and consistent measure of energy efficiency it is necessary to turn it into an operational index with design and operational conditions accounted for and weighted appropriately.

As an alternative in the IMO EEDI, the following approach is proposed. Reference operating scenarios including ship operating profiles and environmental conditions need to be established for each ship type. The new ship designs should be numerically tested on these reference operating scenarios using tools similar to DEM 
presented in this paper. The overall lifecycle ship energy efficiency or $\mathrm{CO}_{2}$ emissions or any other appropriate index should be estimated and compared to the baseline values set by IMO. Thus, the influence of energy saving measures will become evident and the methodology will result to direct comparison of the effect of the alternative designs.

\section{Acknowledgements}

The authors gratefully acknowledge the financial support of the European Commission through the research project TARGETS (http://www.targets-project.eu - Grant agreement No. 266008) and REFRESH (http://www.refreshproject.eu - Grant agreement No. 285708), which were jointly funded by the 7th Framework Programme and the industry, for the work reported in this paper. 


\section{References}

Bertram V. (2012). Practical ship hydrodynamics. 2nd ed. Elsevier Ltd. UK.

Carlton J.S. (2007). Marine Propellers and Propulsion, 2nd Ed. 2007. Butterworth-Heinemann. Oxford. UK.

Henningsen S. (1998). Air Pollution from Large Two-Stroke Diesel Engines and Technologies to Control It. In: Handbook of Air pollution from Internal Combustion Engines: Pollutant Formation and Control. Sher E. (ed). Academic Press Ltd. London.

Heywood J.B. (1988). Internal Combustion Engines Fundamentals. McGraw-Hill.

Holtrop J., Mennen G. (1982). An approximate power prediction method. Int Shipbuilding Prog. 329.166-170.

IMO. (2011). Resolution MEPC.203(62). Amendments to the annex of the protocol of 1997 to amend the international convention for the prevention of pollution from ships, 1973, as modified by the protocol of 1978 relating thereto (Inclusion of regulations on energy efficiency for ships in MARPOL Annex VI). MEPC 62/24/Add.1 London. International Maritime Organization.

IMO. (2012a) Resolution MEPC.212(63). Guidelines on the method of calculation of the attained energy efficiency design index (EEDI) for new ships. MEPC 63/23. London. International Maritime Organization.

IMO. (2012b) Resolution MEPC.213(63). Guidelines for the development of a ship energy efficiency management plan (SEEMP). MEPC 63/23. London. International Maritime Organization.

Janna W.S. (1998). Design of Fluid Thermal Systems, $2^{\text {nd }}$ ed. PWS Publishing Company.

Korotkin A.I. (2009). Added masses of ship structures. 2nd ed. Springer Science and Business Media B.V.

MAN Diesel \& Turbo. Basic principles of ship propulsion. Publication no: 5510-0004-02ppr. August 2012. MAN Diesel \& Turbo. Copenhagen. Denmark.

Meier E. (1981). A simple method of calculation and matching turbochargers. Publication CH-T $120163 E$. Brown Boveri \& Company Ltd. Baden. Switzerland.

Oltmann P. (2003). Identification of hydrodynamic damping derivatives-A pragmatic approach. Proceedings of the International Conference on Marine Simulation and Ship Manoeuvrability (MARSIM'03). Vol. III. 575583. 25-28 August. Kanazawa. Japan.

REFRESH (2014). REFRESH project webpage: http://www.refreshproject.eu

Scappin F. Stefansson S.H. Haglind F. Andreasen A. Larsen U. (2012). Validation of a zero-dimensional model for prediction of NOx and engine performance for electronically controlled marine two-stroke diesel engines. Applied Thermal Engineering. 37. 344-352.

TARGETS (2014). TARGETS project webpage: http://www.targets-project.eu/

Theotokatos G. (2010). On the cycle mean value modelling of a large two-stroke marine diesel engine. Proc IMechE, Part M: J Engineering for the Maritime Environment. 224(3). pp. 193-205. 
Theotokatos G, Tzelepis V. (2013). A computational study on the performance and emission parameters mapping of a ship propulsion system. Proc IMechE, Part M: J Engineering for the Maritime Environment. DOI: 10. 1177/1475090213498715.

US Department of Energy. (1991). Fact Sheet: Determining Electric Motor Load and Efficiency, Motor Challenge Program, Technical Report.

Watson N. and Janota M.S. (1982). Turbocharging the Internal Combustion Engine, Macmillan. 